\title{
Influence of genetic co-factors on the population pharmacokinetic model for clopidogrel and its active thiol metabolite
}

\author{
Dorota Danielak $^{1}$ (D) - Marta Karaźniewicz-Lada ${ }^{1} \cdot$ Anna Komosa $^{2}$ • \\ Pawel Burchardt $^{3,4}$ - Maciej Lesiak ${ }^{2}$ - Lukasz Kruszyna ${ }^{5}$ - Agnieszka Graczyk-Szuster ${ }^{2}$. \\ Franciszek Glówka ${ }^{1}$
}

Received: 2 August 2017 / Accepted: 6 September 2017 / Published online: 15 September 2017

(C) The Author(s) 2017. This article is an open access publication

\begin{abstract}
Purpose A high interindividual variability is observed in the pharmacokinetics of clopidogrel, a widely used antiplatelet drug. In the present study, a joint parent-metabolite population pharmacokinetic model was developed to adequately describe observed concentrations of clopidogrel and its active thiol metabolite (H4).

Methods The study included 63 patients undergoing elective coronarography or percutaneous coronary intervention. The population pharmacokinetic model was developed in the NONMEM 7.3 software, and first-order conditional estimation method with interaction was applied. Also, the influence of covariates was evaluated (age, weight, body mass index (BMI), obesity defined as BMI $\geq 30 \mathrm{~kg} / \mathrm{m}^{2}$, sex, diabetes mellitus, co-administration of PPI or statins, presence of $C Y P 2 C 19 * 2, C Y P 2 C 19 * 17, C Y P 3 A 4 * 1 G$ alleles, and $A B C B 1$ 3435 TT genotype).
\end{abstract}

Electronic supplementary material The online version of this article (https://doi.org/10.1007/s00228-017-2334-z) contains supplementary material, which is available to authorized users.

Dorota Danielak

danielak@ump.edu.pl

1 Department of Physical Pharmacy and Pharmacokinetics, Poznan University of Medical Sciences, Święcickiego 6 St, 60-781 Poznań, Poland

2 First Department of Cardiology, Poznan University of Medical Sciences, Poznań, Poland

3 Department of Biology and Environmental Sciences, Poznan University of Medical Sciences, Poznań, Poland

4 Department of Cardiology, J. Struś Hospital, Poznań, Poland

5 Department of General and Vascular Surgery, Poznan University of Medical Sciences, Poznań, Poland
Results It was found that the only significant covariate was the presence of CYP2C19*2 allele, which had an impact on lower conversion of clopidogrel to $\mathrm{H} 4$. As a result, predicted area under the time-concentration curve values was lower in carriers of this allele, with median $5.94 \mathrm{ng} \mathrm{h} / \mathrm{ml}$ (interquartile range $3.92-12.51[\mathrm{ng} \cdot \mathrm{h} / \mathrm{ml}]$ ) vs. $12.70 \mathrm{ng} \mathrm{h} / \mathrm{ml}$ in non-carriers (interquartile range, $7.00-19.39[\mathrm{ng} \cdot \mathrm{h} / \mathrm{ml}])$, respectively $(p=0.004)$. Conclusions Developed model predicts that the only significant covariate influencing the observed concentrations and therefore the exposure to the active $\mathrm{H} 4$ metabolite is the presence of $C Y P 2 C 19 * 2$ allele.

Keywords Population pharmacokinetics .

Pharmacogenetics $\cdot$ Prodrugs $\cdot$ Single nucleotide

polymorphism $\cdot$ Clinical pharmacokinetics

\section{Introduction}

Clopidogrel, a second-generation thienopyridine, is a widely used antiplatelet agent. According to the American College of Cardiology recommendations, the treatment with clopidogrel in combination with aspirin should be continued in patients with acute coronary syndromes for at least 12 months and for 6 months in patients with stable ischemic heart disease [1]. As showed in clinical trials, clopidogrel effectively lowers the occurrence of myocardial infarction, ischemic stroke, or vascular death in patients at risk of ischemic events [2]. However, the response to clopidogrel in the population is varied and it is estimated that in $16-50 \%$ of patients, a high on-treatment platelet reactivity is observed [3]. Hence, the inhibition of platelet aggregation is inadequate and the risk of major adverse cardiac events is higher.

Clopidogrel is a prodrug that requires biotransformation to the active metabolite. The majority of drug $(85-90 \%)$ is 
metabolized to the carboxylic acid metabolite by carboxylesterases. Only a small portion of the drug undergoes a two-step activation process, which is mediated by cytochrome P-450 (CYP). In an in vitro experiment, Kazui et al. [4] successfully identified that in the first step, clopidogrel is transformed into 2-oxo-clopidogrel by CYP1A2, CYP2B6, and CYP2C19. Subsequently, the thiolactone ring is opened in a reaction catalyzed by CYP2B6, CYP2C9, CYP2C19, and CYP3A4, as shown in the Online Resource file. The product of this reaction, the thiol metabolite, irreversibly binds with $\mathrm{P}_{2} \mathrm{Y}_{12}$ receptor which is located on the platelet surface. As a result, the ADP-mediated platelet aggregation is inhibited [5]. Tuffal et al. [6] have found that two stereoisomers of the active thiol metabolite are present in vivo, labeled $\mathrm{H} 3$ and $\mathrm{H} 4$. However, only $\mathrm{H} 4$ isomer exerts the antiplatelet effect.

Numerous studies show that several genetic and non-genetic aspects might be influencing this phenomenon of resistance to clopidogrel. Most notably, the CYP2C19 loss-of-function alleles (LoF) such as $* 2$ and $* 3$ are connected with poor response to clopidogrel, lower $\mathrm{H} 4$ metabolite concentrations, and higher risk of cardiovascular events [7-9]. This is particularly important in Asian populations, in which the CYP2C19 LoF alleles are more prevalent [10]. Other genetic polymorphisms occurring in the gene sequences are also considered as potential factors of variable response to clopidogrel. As shown in the literature, $A B C B 13435$ TT genotype might be associated with lower exposition to the parent drug [11]. Also, CES-1 (carboxylesterase) c.428 G>A allele was shown to have an influence on higher concentrations of both clopidogrel, active metabolite, and better inhibition of platelet aggregation [12, 13]. Allelic variations in CYP3A4 [14] and P2RY12 [15, 16] genes were found to be associated with insufficient response to clopidogrel. Among the non-genetic factors, concomitant use of proton pump inhibitors (PPIs) is associated with the occurrence of adverse cardiovascular events [17]. Also, lower exposure to the active metabolite is observed when CYP2C19-metabolized PPIs, most notably omeprazole and esomeprazole, are co-administered with clopidogrel [18]. Other drugs, such as rosuvastatin, might have an influence on the higher on-treatment platelet reactivity [19].

The aims of this study were to develop a population pharmacokinetic model for clopidogrel and its $\mathrm{H} 4 \mathrm{me}-$ tabolite and to explore the influence of the most important covariates, including frequently occurring genetic polymorphisms.

\section{Experimental}

\section{Patients and sampling protocol}

The following study included 63 patients of Caucasian origin who received clopidogrel prior to elective coronarography or percutaneous coronary intervention (PCI) procedure. All subjects received oral $75-\mathrm{mg}$ clopidogrel for at least 7 days prior to the procedure and sample collection. The exclusion criteria were as follows: acute myocardial infarction, treatment with a glycoprotein IIb/IIIa antagonist, coumarine derivatives or other antiplatelet drugs with exception of aspirin, platelet count $<100,000 / \mu 1$, on-going malignancies and liver dysfunctions, impaired renal function (serum creatinine $>2 \mathrm{mg} / \mathrm{dl}$ ). The study protocol was approved by the local Ethical Committee at Poznan University of Medical Sciences, and all procedures were in accordance with the 1964 Helsinki declaration and its later amendments or comparable ethical standards. Informed consent was obtained from all individual participants included in the study.

All sampling was performed at the day of the procedure. A full pharmacokinetic profile was obtained from 17 patients. The sampling times were as follows: $0.5,1,2,3$, and $4 \mathrm{~h}$ after clopidogrel administration. From the remaining 46 subjects, only two samples were collected, 0.5 and $2 \mathrm{~h}$ or 1 and $3 \mathrm{~h}$ after receiving the drug. A short time of the last sample collection was based upon the results of previous studies [20]. Very low concentrations of both clopidogrel and $\mathrm{H} 4$ were determined and they were mostly below the detection limit $4 \mathrm{~h}$ after administration of clopidogrel. Five-milliliter full blood aliquots were drawn into vacuum systems containing EDTA-K (Sarstedt, Germany). Immediately after collection, $25-\mu \mathrm{l}$ aliquot of $500 \mathrm{mM}$ bromo-3'-methoxyacetophenone solution was added to stabilize highly labile thiol metabolite, as described by Takahashi et al. [21]. According to Tuffal et al. [6], samples with poor signs of hemolysis might be insufficiently stabilized with the bromo-3'-methoxyacetophenone. Therefore, they were discarded from the analysis. Centrifuged plasma was stored at $-25{ }^{\circ} \mathrm{C}$ until further analysis.

\section{Determination of clopidogrel and $\mathrm{H} 4$ metabolite}

A validated HPLC-MS/MS method was applied for determination of clopidogrel and $\mathrm{H} 4$ [22]. The validation procedure was conducted according to the guideline issued by the European Medicines Agency [23]. The method was linear within $0.25-5 \mathrm{ng} / \mathrm{ml}$ for clopidogrel and $0.25-50 \mathrm{ng} / \mathrm{ml}$ for derivatized $\mathrm{H} 4$, respectively. Within- and between-day precision, expressed as a relative standard deviation, was below $19.9 \%$ for both analytes, while the relative error of the assay was below $16 \%$.

\section{Determination of genetic polymorphisms}

From the collected samples, genomic DNA was extracted with a Quick Blood Purification Kit (EurX, Poland), according to the procedure supplied by the manufacturer. Four SNPs were evaluated: $C Y P 2 C 19 * 2($ rs4244285), $C Y P 2 C 19 * 17$ (rs12248560), CYP $3 A 4 * 1 G(\mathrm{rs} 2242480)$, and $A B C B 1$ 
$3435 C>T(\operatorname{rs} 1045642) . C Y P 2 C 19 * 2, C Y P 3 A 4 * 1 G$, and $A B C B 13435 C>T$ were determined by means of polymerase chain reaction with restriction fragment length polymorphism analysis (PCR-RFLP). CYP2C19*17 was determined with an allele-specific PCR. The conditions of the reactions were described in details elsewhere [9, 11, 24, 25].

\section{Population pharmacokinetic analysis}

\section{Software and methods}

The joint population pharmacokinetic model for clopidogrel and H4 was developed by means of NONMEM software package (version 7.3.0, ICON Development Solutions, Hanover, MD, USA). ADVAN5 or ADVAN6 subroutines were used in linear or non-linear models, respectively. First-order conditional estimation method with interaction (FOCE-I) was applied. Diagnostic plots were generated with the R program (version 3.1.2, Foundation for Statistical Computing, Vienna, Austria) and Xpose (version 4.5.3, Uppsala University, Sweden). Scripts implemented in the Perl Speaks NONMEM (PsN, version 4.4.0) [8] were used for visual predictive check (VPC), covariate searching, and model validation. All modeling and simulation were run through a Pirana graphical user interface (version 2.9.2) [9]. An improvement in the model fit was evaluated with the likelihood ratio test. A difference in the objective function value $(\mathrm{OFV})$ of $3.84(p<0.05)$ between nested models was considered significant, when one variable was added into the model. Also, a visual examination of the diagnostic plots was used to determine the model fit. For each tested model, the following plots were inspected: individual- and populationpredicted concentrations versus observed concentrations, individual- and population-predicted concentrations versus time, weighted (WRES) and conditional-weighted residuals (CWRES) versus predicted concentrations, WRES and CWRES versus time, distribution of CWRES. Data points with $\mid$ CWRES $\mid>4$ were considered as outliers. The outlying points were carefully examined and were only removed from the dataset when they were considered as improbable from pharmacokinetic point of view. The interindividual variability (IIV) elements for the pharmacokinetic parameters were applied exponentially:

$\theta_{i j}=\theta_{j} \times e^{\eta_{i j}}$

where $\theta_{i j}$ is a value of $\mathrm{j}$-th pharmacokinetic parameter for $\mathrm{i}$-th individual, $\theta_{j}$ is the population parameter estimate, and $\eta_{i j}$ is a random variable characterizing IIV, which is normally distributed with mean zero and variance of $\omega^{2}$. Correlations between IIV elements were inspected and included in the structural model.

Additive, proportional, and combined error models for describing the residual variability (RV) were tested. The following equation was applied:
$C_{\text {obs }}=C_{\text {pred }} \times\left(1+\varepsilon_{1}\right)+\varepsilon_{2}$

where $C_{\mathrm{obs}}$ and $C_{\text {pred }}$ are observed and predicted concentrations, $\varepsilon_{1}$ is a variable associated with proportional RV (removed from the equation while testing the additional error model), and $\varepsilon_{2}$ defines additive portion of RV (removed from the equation while testing the proportional error model).

For the concentrations below the quantitation limit, an M3 method was applied [26, 27].

\section{PK model development}

In the first step of the model development, a structural model was determined. Initially, the base model for clopidogrel was established, which included an absorption compartment and a central compartment. Subsequently, further compartments were added to characterize the metabolite pharmacokinetics. Noteworthy, the determined $\mathrm{H} 4$ concentrations were adjusted to the mass equivalent of the parent compound. To adequately present the complex absorption and metabolite-formation process, several issues were tested: first-pass effect, absorption lag time, zero- and first-order linear kinetics, non-linear kinetics of metabolite formation, inclusion of transition compartments. It was assumed that the formation of the $\mathrm{H} 4$ metabolite was irreversible.

\section{Covariate analysis}

Potential covariates were evaluated after visual inspection of their possible relationships with PK parameters included in the model. Then, a covariate model was created in a stepwise forward-inclusion backward-elimination manner with a PsN $s c m$ script. A 3.84 or greater drop in the OFV $(p \leq 0.05)$ was chosen as a threshold for covariate inclusion. After all significant covariates were included, a full model was obtained. In the next step, the covariates were sequentially eliminated. A covariate was retained in a final model, if the OFV increased by more than $6.63(p \leq 0.01)$. Also, clinical significance of the covariates was considered. The following covariates were inspected: age, weight, body mass index (BMI), obesity defined as $\mathrm{BMI} \geq 30 \mathrm{~kg} / \mathrm{m}^{2}$, sex, diabetes mellitus, coadministration of PPI or statins, presence of $C Y P 2 C 19 * 2$, CYP2C19*17, CYP3A4*1G alleles, and ABCB1 3435 TT genotype. For continuous covariates, a linear, piece-wise, exponential, and power parameter-covariate relations were tested. Categorical covariates were linearly included.

\section{Simulations and model diagnostics}

VPC diagnostics was performed for 1000 simulated observations, and $90 \%$ prediction intervals (PI) were constructed from simulated concentration-time profiles and compared with observed data. Additionally, 1000 datasets were bootstrapped, 
and as a result, median value of each PK parameter, as well as 5th and 95th confidence intervals (CI) was obtained. Prior to bootstrapping, the dataset was stratified upon the number of samples obtained from each subject ( 17 full profiles vs 46 sparingly sampled) and upon the categorical covariates retained in the final model.

\section{Estimation of exposure to clopidogrel and $\mathrm{H} 4$}

Model-based estimation of the area under the timeconcentration curve (AUC) for both the clopidogrel and H4 was based on the obtained empirical Bayes estimates of apparent clearances as follows:

$$
\begin{gathered}
A U C_{C L P}=\frac{F \times D}{C L_{C L P}} \\
A U C_{H 4}=\frac{F M \times F \times D}{C L_{H 4}}
\end{gathered}
$$

where $A U C_{C L P}$ and $A U C_{H 4}$ are AUC of clopidogrel and the active metabolite, respectively, $F$ is bioavailability, $D$ is the dose of clopidogrel $(75 \mathrm{mg}), F M$ is a fraction of clopidogrel converted to $\mathrm{H} 4$, and $C L_{C L P}$ and $C L_{H 4}$ stand for the clearances of the clopidogrel and $\mathrm{H} 4$, respectively.

The AUC comparison in the presence of influential covariates was performed with a non-parametric $U$ Mann-Whitney's test in the Statistica 12 software (Statsoft, Inc. 2014).

\section{Results}

\section{Patients' characteristics and genotype frequencies}

The characteristics of patients, for whom quantifiable concentrations of clopidogrel and $\mathrm{H} 4$ were available, are presented in Table 1. Since pantoprazole was almost exclusively administered as a PPI of choice, the discrimination between the types of PPIs was not considered in this analysis. The final dataset consisted of 155 clopidogrel concentrations and $158 \mathrm{H} 4$ concentrations. A total of 17 samples were below quantitation level (10 for clopidogrel and 7 for H4). Three hours after drug administration, $6.5 \%$ of clopidogrel and $6.4 \%$ of $\mathrm{H} 4$ concentrations were below quantitation level, while $4 \mathrm{~h}$ after drug administration below quantitation threshold were 35.7 and $28.6 \%$ of clopidogrel and $\mathrm{H} 4$ concentrations, respectively. For 1 woman and 7 men, the data on bodyweight and BMI was missing. For further covariate analysis, the missing data were imputed with mean values. For female patients, the means were $73.5 \mathrm{~kg}$ for weight and $29.88 \mathrm{~kg} / \mathrm{m}^{2}$ for BMI, respectively, while $82.3 \mathrm{~kg}$ weight and $26.90 \mathrm{~kg} / \mathrm{m}^{2}$ BMI were imputed for male patients.
Table 1 Patients' demographics and genotype distribution $(n=63)$. Age, weight, and BMI are presented as mean with standard deviation. Categorical data are presented as quantities with frequencies

\begin{tabular}{ll}
\hline Parameter & Value \\
Age [years] & $65.4 \pm 10.5$ \\
Weight $[\mathrm{kg}](n=55)$ & $79.1 \pm 14.0$ \\
BMI $\left[\mathrm{kg} / \mathrm{m}^{2}\right](n=55)$ & $28.40 \pm 4.89$ \\
BMI $\geq 30$ & $37(67.3 \%)$ \\
Sex (male/female) & $42(66.7 \%) / 21(33.3 \%)$ \\
DM & $22(34.9 \%)$ \\
Statins & $60(95.2 \%)$ \\
PPI & $46(73.0 \%)$ \\
Pantoprazole & $43(93.5 \%)^{\mathrm{a}}$ \\
Omeprazole & $2(4.3 \%)^{\mathrm{a}}$ \\
Esomeprazole & $1(2.2 \%)^{\mathrm{a}}$ \\
Allele & Number of carriers \\
$C Y P 2 C 19 * 2$ & $20(31.7 \%)$ \\
$C Y P 2 C 19 * 17$ & $34(54.0 \%)$ \\
$C Y P 3 A 4 * 1 G$ & $10(15.8 \%)$ \\
$A B C B 13435 T T$ & $22(34.9 \%)$ \\
Phenotype & Number of patients \\
UM $(* 1 / * 17$ and $* 17 * 17)$ & $25(39.7 \%)$ \\
EM $(* 1 / * 1)$ & $18(28.6 \%)$ \\
IM $(* 1 / * 2)$ & $20(31.7 \%)$ \\
\hline
\end{tabular}

$B M I$ body mass index, $D M$ diabetes mellitus, $P P I$ proton pump inhibitors, $U M$ ultrarapid metabolizers, $E M$ extensive metabolizers, $I M$ intermediate metabolizers

${ }^{\text {a }}$ The frequency of patients treated with $P P I$

\section{PK model}

The final base structural model for pharmacokinetics of clopidogrel and H4 is presented in Fig. 1. Previous studies showed that clopidogrel undergoes extensive first-pass metabolism to the inactive carboxylic acid [28]. Inclusion of a firstpass effect rate constant from the depot compartment to $\mathrm{H} 4$ metabolite compartment did not improve the model (Supplementary Material Table 1). Since it is estimated that approximately $85 \%$ of the absorbed dose is inactivated in this process, the fraction of the drug converted to the active metabolite (FM) was constrained to be no larger than $20 \%$. The relative bioavailability $(\mathrm{F})$ of clopidogrel, described as a relative proportion of the drug absorbed after oral administration, was assumed a typical value of unity. The derived population base model consisted of log-normal distribution of IIV for $\mathrm{k}_{12}$,

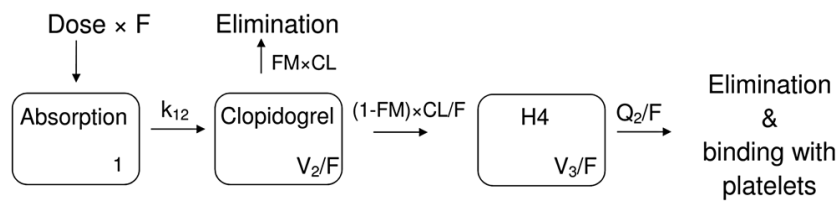

Fig. 1 Final structural model for clopidogrel and $\mathrm{H} 4$ 
$\mathrm{V}_{2} / \mathrm{F}, \mathrm{CL} / \mathrm{F}$, and $\mathrm{FM}$. The model included covariance between $\mathrm{k}_{12}$ and $\mathrm{V}_{2} / \mathrm{F}$. For clopidogrel and $\mathrm{H} 4$, a proportional error model, with separate terms for both entities, was applied. It was found that first-order kinetics best described transition of the drug between the compartments. Also, inclusion of additional peripheral or transition compartments did not improve the model fit.

The performed covariate analysis identified the presence of $C Y P 2 C 19 * 2$ as the most significant covariate that influenced the pharmacokinetics of the studied drug. In the first step of the covariate modeling, the following parameter-covariate relationships were found to be significant: $\mathrm{k}_{12}-\mathrm{sex}$; CL/F-ABCB1 TT; FM-CYP $2 C 19 * 2, C Y P 2 C 19 * 17 ; \mathrm{V}_{2} / \mathrm{F}-$ sex. However, after including CYP2C19*2 as a cofactor for FM, the influence of the other covariates was negligible. Incorporation of this parameter improved the overall model fit and lowered the OFV, and therefore, it was retained in the final model. Final PK estimates derived from the final PK model are presented in Table 2. Detailed results of the covariate selection process are presented in the Online Resource file.

Goodness-of-fit plots presenting the correlations between individual- and population-predicted and observed concentrations of clopidogrel and $\mathrm{H} 4$ are presented in Fig. 2. The data points in population- and individual-predicted concentrations versus observed concentrations plots are widely spread around the identity line, reflecting a large unexplained RV. Additional diagnostic plots are presented in the Online Resource file.
VPC, which graphically illustrates the model adequacy, is presented in Fig. 3. H4 concentrations were noticeably lower in carriers of $C Y P 2 C 19 * 2$ allele, while the concentrations of clopidogrel were similar in carriers of both wild-type $(w t)$ and polymorphic $C Y P 2 C 19$ alleles. Ninety percent interpercentile range for predicted data were utilized, corresponding to 5 th and 95th percentiles of observed data. In small datasets, this approach is preferable to a more widely used $95 \%$ prediction intervals [29]. $4.8 \%$ of the observed clopidogrel concentrations and $4.2 \%$ of observed $\mathrm{H} 4$ concentrations fell outside the $90 \%$ prediction intervals. The resemblance of observed and simulated profiles is visible for both clopidogrel and $\mathrm{H} 4$. The simulated and observed medians are close to each other in almost all bins. The VPC for concentrations below quantitation limit shows that the concentrations of clopidogrel and $\mathrm{H} 4$ might be undetectable in as much as $20 \%$ of samples collected $3 \mathrm{~h}$ or later after the drug administration.

\section{Comparison of exposure to clopidogrel and $\mathrm{H} 4$}

The results of Mann-Whitney's $U$ test showed that the AUC of clopidogrel was not significantly different between carriers of CYP2C19*2 allele and wild-type homozygotes (Fig. 4a). In contrast, as shown in Fig. 4b, the presence of CYP2C19*2 loss-of-function allele was associated with noticeably lower AUC of the active $\mathrm{H} 4$ metabolite $(13.58 \pm 7.10 \mathrm{vs}$. $8.59 \pm 6.48 \mathrm{ng} \mathrm{h} / \mathrm{ml}, p=0.004)$.
Table 2 Estimates of CLP and $\mathrm{H} 4$ pharmacokinetic parameters obtained from the final pharmacokinetic model with residual standard errors (RSE) and bootstrap results with $95 \%$ confidence intervals $(\mathrm{CI})$

\begin{tabular}{llll}
\hline Parameter & Final model & \multicolumn{2}{l}{ Bootstrap results } \\
\cline { 2 - 4 } & Estimate (RSE, \%) & Mean & $95 \% \mathrm{CI}$ \\
\hline $\mathrm{k}_{12}[1 / \mathrm{h}]$ & $0.592(3.53)$ & 0.592 & $0.556-0.626$ \\
$\mathrm{~V}_{2} / \mathrm{F}[\mathrm{L}]$ & $7660(4.3)$ & 7700 & $7310-8240$ \\
$\mathrm{CL} / \mathrm{F}[\mathrm{L} / \mathrm{h}]$ & $14,500(3.9)$ & 14,400 & $13,250-14,970$ \\
$\mathrm{FM}$ & $0.045(3.6)$ & 0.045 & $0.044-0.048$ \\
$\mathrm{~V}_{3} / \mathrm{F}[\mathrm{L}]$ & $4.89(4.5)$ & 4.90 & $4.65-5.15$ \\
$\mathrm{Q}_{2} / \mathrm{F}[\mathrm{L} / \mathrm{h}]$ & $252(4.2)$ & 251 & $232-264$ \\
$\mathrm{IIV}$ for $\mathrm{k}_{12}$ & $25.3(7.3)$ & 24.9 & $23.7-26.9$ \\
$\mathrm{IIV}$ for $\mathrm{V}_{2} / \mathrm{F}$ & $63.7(19.6)$ & 63.7 & $51.8-76.0$ \\
$\mathrm{IIV}^{\mathrm{a}}$ for CL/F & $49.8(8.3)$ & 47.1 & $45.9-53.5$ \\
$\mathrm{IIV}^{\mathrm{a}}$ for FM & $71.4(7.9)$ & 71.3 & $65.0-76.4$ \\
Effect of $C Y P 2 C 19 * 2$ & & & \\
on FM $(\mathrm{COV})^{\mathrm{b}}$ & $-0.45(8.4)$ & -0.45 & $-0.48--0.41$ \\
Covariance between & & & \\
$\mathrm{k}_{12}$ and $\mathrm{V}_{2} / \mathrm{F}$ & $-0.087(49.3)$ & -0.076 & $-0.116-0.011$ \\
Proportional residual error for CLP & $-0.45(4.5)$ & -0.45 & $-0.49--0.42$ \\
Proportional residual error for H4 & $-0.66(5.4)$ & -0.65 & $-0.68--0.58$ \\
\hline
\end{tabular}

${ }^{\mathrm{a}} \% \mathrm{CV}=(\operatorname{SQRT}(\operatorname{EXP}(\mathrm{OMEGA}(\mathrm{N}))-1)) * 100 \%$

${ }^{\mathrm{b}} \mathrm{FM}=\mathrm{TVFM}^{*}(1+C Y P 2 C 19 * \mathrm{COV})$ 

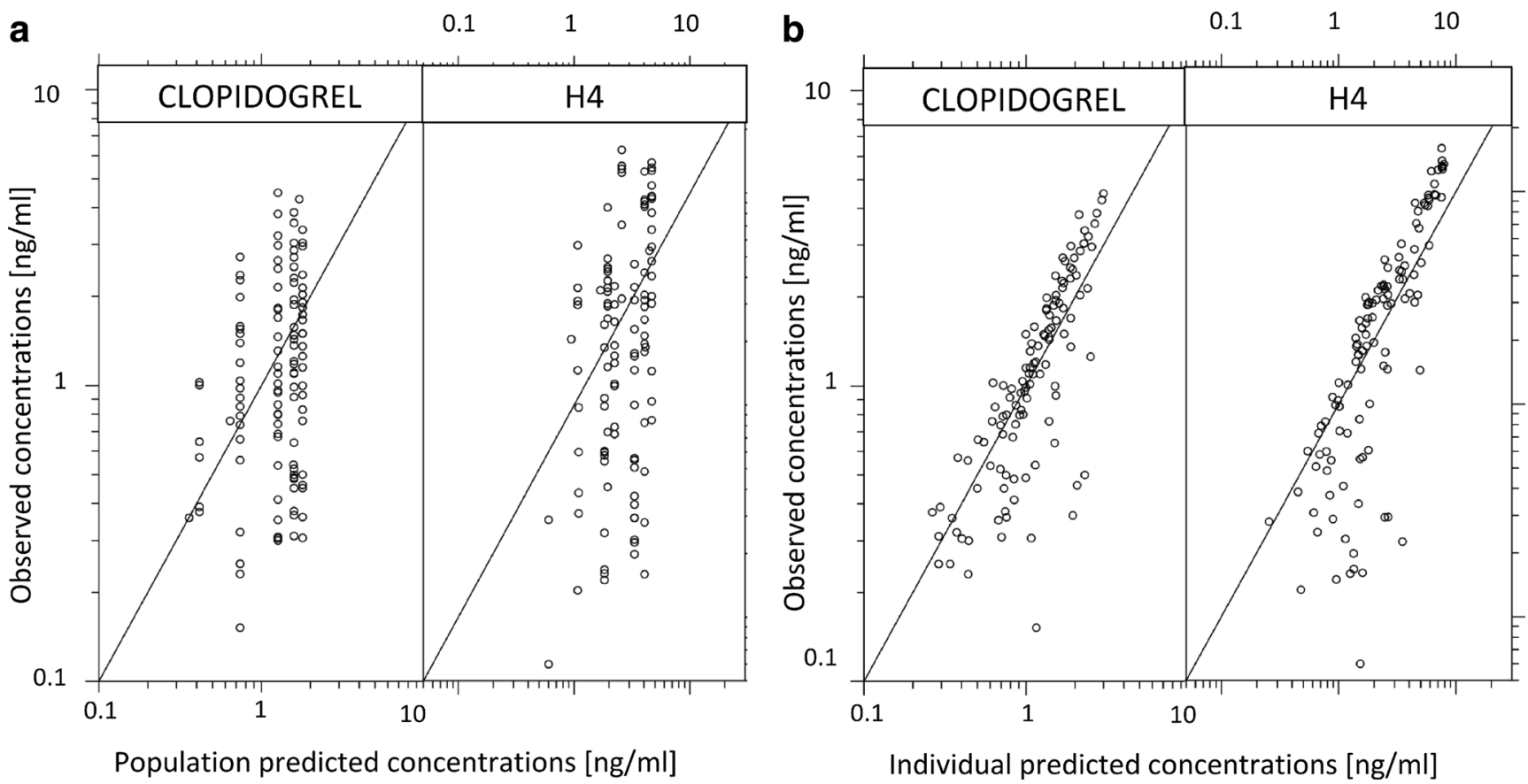

Fig. 2 Diagnostic goodness-of-fit plots for clopidogrel and H4. a Observed concentrations versus population-predicted concentrations. b Observed concentrations versus individual-predicted concentrations

\section{Discussion}

The pharmacokinetics of clopidogrel might be influenced by many factors, both genetic and non-genetic. Several population models have been established for describing pharmacokinetics and pharmacodynamics of clopidogrel. However, some of the previously published models are based upon measurements of the inactive carboxylic acid metabolite [30, 31]. Ernest et al. [32] have established a model that enabled prediction of the thiol metabolite concentrations. Yet it was not specified whether the reported concentrations reflect $\mathrm{H} 3$ and $\mathrm{H} 4$ isomers or only the $\mathrm{H} 4$ isomer which has the antiplatelet activity. Moreover, no data on the important genetic covariates and concentrations of the parent drug were included in that analysis. Recently, more elaborated physiologically based models were developed, that allowed the prediction of clopidogrel pharmacokinetics, yet they are very complicated and require numerous assumptions [33, 34]. Therefore, the present study was aimed at creating a joint parent-metabolite population pharmacokinetic model to explore the potential co-factors and to define the most influential ones.

In the present study, both clopidogrel and the $\mathrm{H} 4$ metabolite kinetics could be described with one-compartment model. The observed IIV for the parameters was very high (25.3$71.4 \%$ ). It was also found that the linear elimination of both entities was sufficient to describe the observed concentrations.

The typical population value of FM was estimated to be less than $5 \%$. It is in contrast with the previously mentioned model [32], which followed the assumption that all of the absorbed dose was metabolized to the active metabolite, due to lack of the data on the concentrations of the parent entity.
The majority of clopidogrel undergoes an extensive first-pass metabolism to the inactive carboxylic acid (Online Resource file). However, the extent of this reaction, catalyzed by the CES-1 enzyme, could not be established in this study. Also, in the present study, linear model more adequately described the conversion to the $\mathrm{H} 4$ then non-linear one. In the recently published physiologically based models, this reaction was following Michaelis-Menten non-linear kinetics [33, 34]. The observation from the present study might be explained by the fact that the study group involved patients who were being administered $75 \mathrm{mg}$ clopidogrel daily, and the observed maximum total plasma concentrations of clopidogrel did not exceed $5 \mathrm{ng} / \mathrm{ml}(0.015 \mu \mathrm{M})$. Therefore, they are much lower than the Michalis-Menten constants $\left(\mathrm{K}_{\mathrm{m}}\right)$ for the enzymatic conversion of the clopidogrel to $\mathrm{H} 4$ by each of the involved CYP450 isoenzymes, as established by other authors $[4,34]$. However, since a full pharmacokinetic profile could be obtained from 17 patients only and both the clopidogrel and $\mathrm{H} 4$ are rapidly eliminated, the data might not be sufficient to adequately support a more complex model.

Since many factors, both genetic and non-genetic factors, might influence pharmacokinetics of clopidogrel, the impact of following potential covariates was evaluated: age, weight, sex, diabetes mellitus, co-administration of PPI or statins, the presence of $C Y P 2 C 19 * 2, C Y P 2 C 19 * 17, C Y P 3 A 4 * 1 G$ alleles, and $A B C B 13435 T T$ genotype. The most significant of the examined covariates was the presence of $C Y P 2 C 19 * 2$ allele. It was found that the FM was lower in the $* 2$ carriers. This finding is consistent with numerous studies, which reported a strong association of $* 2$ with lower exposure to the $\mathrm{H} 4$ 

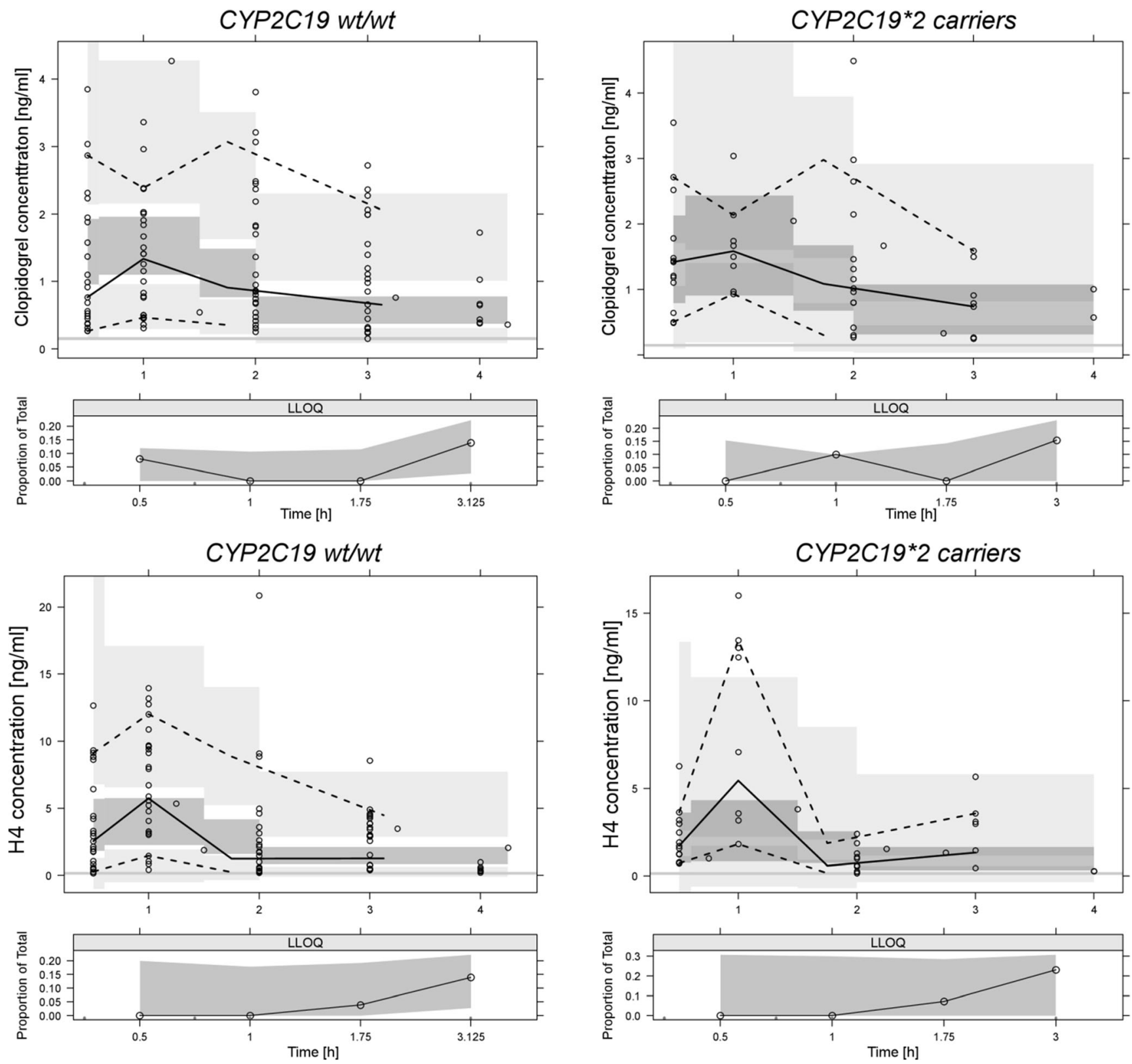

Fig. 3 VPC plots for clopidogrel and H4 stratified upon the presence of CYP2C19*2 allele. Observed concentrations are presented as circles, bold line as median of the observed concentrations, and dashed lines as $95 \%$

metabolite [9, 35-37]. As a consequence, predicted AUC of the $\mathrm{H} 4$ metabolite was $36.7 \%$ lower in these patients, while the AUC of the parent drug remained unchanged (Fig. 4). This is in accordance with the predictions from the physiologicalbased models, in which intermediate $(* 1 / * 2)$ and poor metabolizers $(* 2 / * 2)$ have lower concentrations of the active metabolite [33, 34]. As indicated by other researchers, the exposure to the $\mathrm{H} 4$ metabolite can be over $30 \%$ lower in carriers of at least one CYP2C19 LoF allele [36, 38]. In the present study, none of the patients could be classified as poor metabolizers; therefore, patients' classification by phenotype was not performed. The other studied CYP2C19 allele, labeled

confidence intervals of the observed concentrations. Dark gray areas are $50 \%$ prediction intervals of the simulated data and light gray areas are $90 \%$ prediction intervals of the simulated data

$* 17$, is associated with an increased activity of CYP2C19 isoenzyme. In several studies, the $* 17$ allele was related to lower on-treatment platelet reactivity and even with a "protective" effect $[39,40]$. In the proposed model, the presence of this allele was a significant covariate for both FM and $\mathrm{V}_{2} / \mathrm{F}$. However, after including the CYP $2 C 19 * 2$ as a most significant cofactor, the $* 17$ was not influential. This might confirmed results from other studies which did not find $* 17$ allele influencing H4 pharmacokinetics [41, 42].

$A B C B 13435 T T$ genotype is associated with an increased risk of major adverse cardiovascular events, as compared with $C C$ and $C T$ genotypes [43]. In several pharmacokinetic 

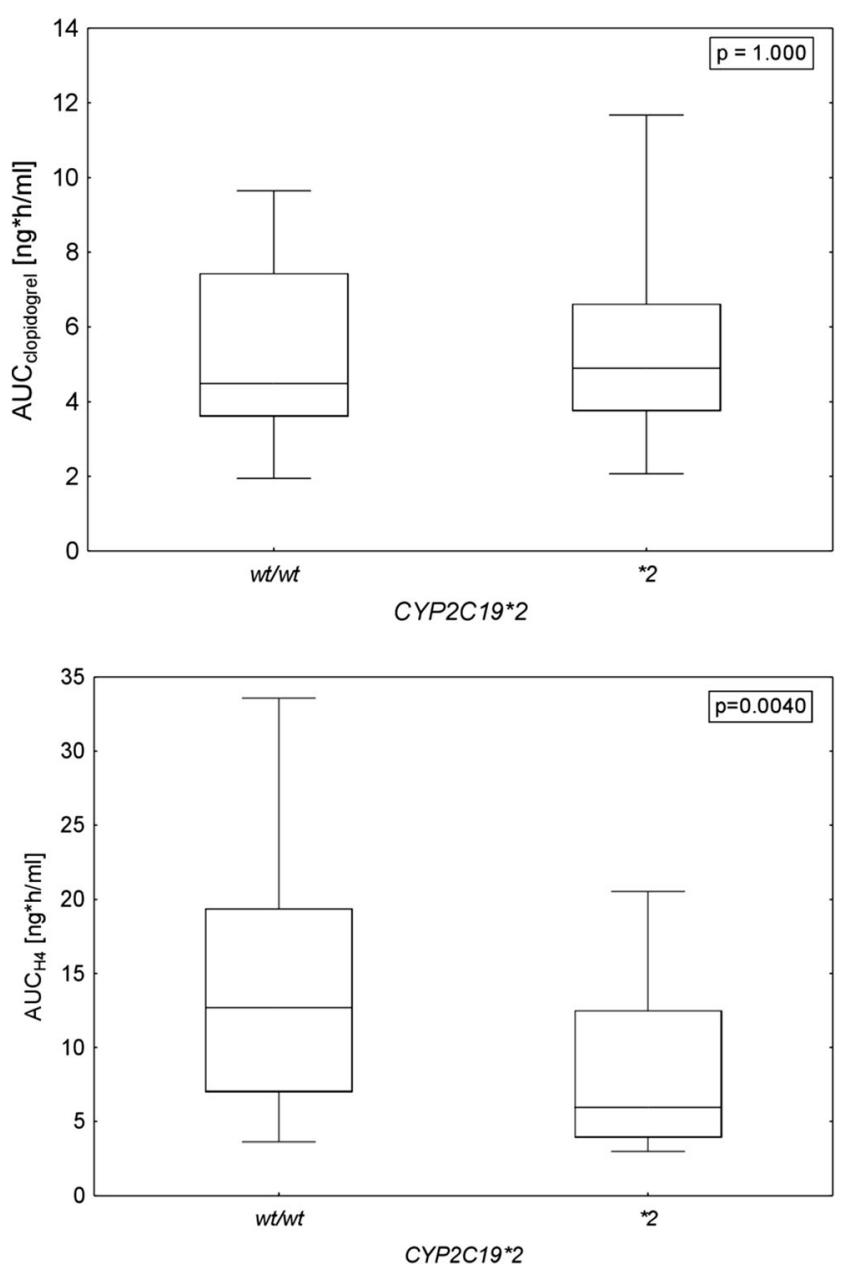

Fig. 4 Comparison of the area-under-time-concentration curves (AUC) of clopidogrel and $\mathrm{H} 4$ in wild-type homozygotes $(w t / w t)$ and $C Y P 2 C 19 * 2$ carriers. Data are presented as medians with boxed interquartile range and minimum-maximum as whiskers

studies, it was shown that in the TT homozygotes, the exposure to the unchanged clopidogrel is significantly lower [11, $44,45]$. In the present study, step-wise analysis showed that $T T$ genotype was a significant covariate for $\mathrm{CL} / \mathrm{F}$, and in its presence, the apparent clearance of clopidogrel was higher. However, after inclusion of $C Y P 2 C 19 * 2$ genotype, further addition of $A B C B 1 T T$ did not improve the model fit. Therefore, it might be concluded that this particular P-gp polymorphism is not an independent factor influencing clopidogrel pharmacokinetics. Similarly, Carlquist et al. [46] found that $A B C B 1$ $3435 C>T$ polymorphism might be associated with the occurrence of cardiovascular events only when $C Y P 2 C 19 * 2$ is also considered.

Other covariates were not found to be of significant influence. Although some authors mention that covariates such as BMI [47] or obesity [48] might influence pharmacokinetics of clopidogrel or $\mathrm{H} 4$ metabolite, it was not confirmed in the present analysis.

In conclusion, the developed model predicts that the only significant covariate influencing the observed concentrations and therefore the exposure to the active $\mathrm{H} 4$ metabolite is the presence of $C Y P 2 C 19 * 2$ allele.

Acknowledgments The following study was supported by National Science Centre (NCN) in Poland, grant number 2014/15/B/NZ7/00869 and Poznan University of Medical Sciences grant for young scientists number 502-14-03306413-09628.

The authors would like to thank Mr. Artur Teżyk and Mr. Piotr Bergus for the assistance with the determination of clopidogrel and $\mathrm{H} 4$ and Mrs. Karolina Wiśniewska and Mrs. Aleksandra Tomczak for the assistance with determination of genetic polymorphisms.

Author contributions D. Danielak performed the modeling and simulation analysis, supervised determination of the analytes and determination of genetic polymorphisms, and wrote the manuscript. M. Karaźniewicz-Łada supervised the study and wrote the manuscript. A. Komosa, P. Burchardt, M. Lesiak, Ł. Kruszyna, and A. Graczyk-Szuster supervised patients' recruitment and sample acquisition. F. Główka supervised the study and revised the manuscript.

All authors read and approved the final version of the manuscript.

Compliance with ethical standards The study protocol was approved by the local Ethical Committee at Poznan University of Medical Sciences, and all procedures were in accordance with the 1964 Helsinki declaration and its later amendments or comparable ethical standards.

Conflict of interest The authors declare that they have no conflict of interest.

Open Access This article is distributed under the terms of the Creative Commons Attribution 4.0 International License (http:// creativecommons.org/licenses/by/4.0/), which permits unrestricted use, distribution, and reproduction in any medium, provided you give appropriate credit to the original author(s) and the source, provide a link to the Creative Commons license, and indicate if changes were made.

\section{References}

1. Levine GN, Bates ER, Bittl JA et al (2016) 2016 ACC/AHA guideline focused update on duration of dual antiplatelet therapy in patients with coronary artery disease: a report of the American College of Cardiology/American Heart Association Task Force on Clinical Practice Guidelines. J Thorac Cardiovasc Surg 152:12431275. https://doi.org/10.1016/j.jtcvs.2016.07.044

2. Steering Committee CAPRIE (1996) A randomised, blinded, trial of clopidogrel versus aspirin in patients at risk of ischaemic events (CAPRIE). Lancet 348:1329-1339

3. Mallouk N, Labruyère C, Reny J-L et al (2012) Prevalence of poor biological response to clopidogrel: a systematic review. Thromb Haemost 107:494-506. https://doi.org/10.1160/TH11-03-0202

4. Kazui M, Nishiya Y, Ishizuka T et al (2010) Identification of the human cytochrome P450 enzymes involved in the two oxidative steps in the bioactivation of clopidogrel to its pharmacologically active metabolite. Drug Metab Dispos 38:92-99. https://doi.org/ 10.1124/dmd.109.029132

5. Karaźniewicz-Łada M, Danielak D, Główka F (2012) Genetic and non-genetic factors affecting the response to clopidogrel therapy. Expert Opin Pharmacother 13:663-683. https://doi.org/10.1517/ 14656566.2012.666524

6. Tuffal G, Roy S, Lavisse M et al (2011) An improved method for specific and quantitative determination of the clopidogrel active 
metabolite isomers in human plasma. Thromb Haemost 105:696705. https://doi.org/10.1160/TH10-09-0582

7. Hou X, Shi J, Sun H (2014) Gene polymorphism of cytochrome P450 2C19*2 and clopidogrel resistance reflected by platelet function assays: a meta-analysis. Eur J Clin Pharmacol 70:1041-1047. https://doi.org/10.1007/s00228-014-1714-x

8. Jang J-S, Cho K-I, Jin H-Y et al (2012) Meta-analysis of cytochrome $\mathrm{P} 4502 \mathrm{C} 19$ polymorphism and risk of adverse clinical outcomes among coronary artery disease patients of different ethnic groups treated with clopidogrel. Am J Cardiol 110:502-508. https:// doi.org/10.1016/j.amjcard.2012.04.020

9. Karaźniewicz-Łada M, Danielak D, Rubiś B et al (2014) The influence of genetic polymorphism of Cyp2c19 isoenzyme on the pharmacokinetics of clopidogrel and its metabolites in patients with cardiovascular diseases. J Clin Pharmacol 54:874-880. https://doi. org/10.1002/jcph.323

10. Sorich MJ, Rowland A, McKinnon RA, Wiese MD (2014) CYP2C19 genotype has a greater effect on adverse cardiovascular outcomes following percutaneous coronary intervention and in Asian populations treated with clopidogrel: a meta-analysis. Circ Cardiovasc Genet 7:895-902. https://doi.org/10.1161/ CIRCGENETICS.114.000669

11. Karaźniewicz-Łada M, Danielak D, Rubiś B et al (2015) Impact of common $\mathrm{ABCB} 1$ polymorphism on pharmacokinetics and pharmacodynamics of clopidogrel and its metabolites. J Clin Pharm Ther 40:226-231. https://doi.org/10.1111/jept.12236

12. Zhu H-J, Wang X, Gawronski BE et al (2013) Carboxylesterase 1 as a determinant of clopidogrel metabolism and activation. $\mathrm{J}$ Pharmacol Exp Ther 344:665-672. https://doi.org/10.1124/jpet. 112.201640

13. Tarkiainen EK, Holmberg MT, Tornio A et al (2015) Carboxylesterase $1 \mathrm{c} .428 \mathrm{G}>$ a single nucleotide variation increases the antiplatelet effects of clopidogrel by reducing its hydrolysis in humans. Clin Pharmacol Ther 97:650-658. https://doi.org/10. 1002/cpt.101

14. Angiolillo DJ, Fernandez-Ortiz A, Bernardo E et al (2006) Contribution of gene sequence variations of the hepatic cytochrome P450 3A4 enzyme to variability in individual responsiveness to clopidogrel. Arter Thromb Vasc Biol 26:1895-1900. https://doi. org/10.1161/01.ATV.0000223867.25324.1a

15. Rudež G, Bouman HJ, van Werkum JW et al (2009) Common variation in the platelet receptor P2RY12 gene is associated with residual on-clopidogrel platelet reactivity in patients undergoing elective percutaneous coronary interventions/clinical perspective. Circ Cardiovasc Genet 2:515-521. https://doi.org/10.1161/ CIRCGENETICS.109.861799

16. Yang H-H, Chen Y, Gao C-Y (2016) Associations of P2Y12R gene polymorphisms with susceptibility to coronary heart disease and clinical efficacy of antiplatelet treatment with clopidogrel. Cardiovasc Ther 34:460-467. https://doi.org/10.1111/1755-5922. 12223

17. Serbin MA, Guzauskas GF, Veenstra DL (2016) Clopidogrelproton pump inhibitor drug-drug interaction and risk of adverse clinical outcomes among PCI-treated ACS patients: a meta-analysis. J Manag Care Spec Pharm 22:939-947. 10.18553/jmcp.2016. 22.8.939

18. Frelinger AL 3rd, Lee RD, Mulford DJ et al (2012) A randomized, 2-period, crossover design study to assess the effects of dexlansoprazole, lansoprazole, esomeprazole, and omeprazole on the steady-state pharmacokinetics and pharmacodynamics of clopidogrel in healthy volunteers. J Am Coll Cardiol 59:13041311. https://doi.org/10.1016/j.jacc.2011.12.024

19. Suh J-W, Cha M-J, Lee S-P et al (2014) Relationship between statin type and responsiveness to clopidogrel in patients treated with percutaneous coronary intervention: a subgroup analysis of the CILON-T trial. J Atheroscler Thromb 21:140-150
20. Karaźniewicz-Łada M, Danielak D, Burchardt P et al (2014) Clinical pharmacokinetics of clopidogrel and its metabolites in patients with cardiovascular diseases. Clin Pharmacokinet 53:155164. https://doi.org/10.1007/s40262-013-0105-2

21. Takahashi M, Pang H, Kawabata K et al (2008) Quantitative determination of clopidogrel active metabolite in human plasma by LCMS/MS. J Pharm Biomed Anal 48:1219-1224. https://doi.org/10. 1016/j.jpba.2008.08.020

22. Karaźniewicz-Łada M, Danielak D, Teżyk A et al (2012) HPLC$\mathrm{MS} / \mathrm{MS}$ method for the simultaneous determination of clopidogrel, its carboxylic acid metabolite and derivatized isomers of thiol metabolite in clinical samples. J Chromatogr B Analyt Technol Biomed Life Sci 911:105-112. https://doi.org/10.1016/j.jchromb. 2012.11.005

23. European Medicines Agency - Guideline on bioanalytical method validation. http://www.ema.europa.eu/ema/index.jsp?curl=pages/ includes/document/document_detail.jsp?webContentId= WC500109686\&murl=menus/document library/document library.jsp\&mid=WC0b01ac058009a3dc. Accessed 14 June 2017

24. Danielak D, Karaźniewicz-Łada M, Wiśniewska K et al (2017) Impact of CYP3A4*1G allele on clinical pharmacokinetics and pharmacodynamics of clopidogrel. Eur J Drug Metab Pharmacokinet 42:99-107. https://doi.org/10.1007/s13318-0160324-7

25. Sim SC, Risinger C, Dahl M-L et al (2006) A common novel CYP2C19 gene variant causes ultrarapid drug metabolism relevant for the drug response to proton pump inhibitors and antidepressants. Clin Pharmacol Ther 79:103-113. https://doi.org/10.1016/j.clpt. 2005.10.002

26. Beal SL (2001) Ways to fit a PK model with some data below the quantification limit. J Pharmacokinet Pharmacodyn 28:481-504

27. Bergstrand M, Karlsson MO (2009) Handling data below the limit of quantification in mixed effect models. AAPS J 11:371-380. https://doi.org/10.1208/s12248-009-9112-5

28. Sangkuhl K, Klein TE, Altman RB (2010) Clopidogrel pathway. Pharmacogenet Genomics 20:463-465. https://doi.org/10.1097/ FPC.0b013e3283385420

29. Bergstrand M, Hooker AC, Wallin JE, Karlsson MO (2011) Prediction-corrected visual predictive checks for diagnosing nonlinear mixed-effects models. AAPS J 13:143-151. https://doi.org/ 10.1208/s12248-011-9255-Z

30. Yousef AM, Melhem M, Xue B et al (2013) Population pharmacokinetic analysis of clopidogrel in healthy Jordanian subjects with emphasis optimal sampling strategy. Biopharm Drug Dispos 34: 215-226. https://doi.org/10.1002/bdd.1839

31. Lee J, Hwang Y, Kang W et al (2012) Population pharmacokinetic/ pharmacodynamic modeling of clopidogrel in Korean healthy volunteers and stroke patients. J Clin Pharmacol 52:985-995. https:// doi.org/10.1177/0091270011409228

32. Ernest CS 2nd, Small DS, Rohatagi S et al (2008) Population pharmacokinetics and pharmacodynamics of prasugrel and clopidogrel in aspirin-treated patients with stable coronary artery disease. $\mathrm{J}$ Pharmacokinet Pharmacodyn 35:593-618. https://doi.org/10. 1007/s10928-008-9103-7

33. Djebli N, Fabre D, Boulenc X et al (2015) Physiologically based pharmacokinetic modeling for sequential metabolism: effect of CYP2C19 genetic polymorphism on clopidogrel and clopidogrel active metabolite pharmacokinetics. Drug Metab Dispos 43:510 522. https://doi.org/10.1124/dmd.114.062596

34. Jiang X-L, Samant S, Lewis JP et al (2016) Development of a physiology-directed population pharmacokinetic and pharmacodynamic model for characterizing the impact of genetic and demographic factors on clopidogrel response in healthy adults. Eur J Pharm Sci 82:64-78. https://doi.org/10.1016/j.ejps.2015.10.024

35. Horenstein RB, Madabushi R, Zineh I et al (2014) Effectiveness of clopidogrel dose escalation to normalize active metabolite exposure 
and antiplatelet effects in CYP2C19 poor metabolizers. J Clin Pharmacol 54:865-873. https://doi.org/10.1002/jcph.293

36. Hulot J-S, Collet J-P, Cayla G et al (2011) CYP2C19 but not PON1 genetic variants influence clopidogrel pharmacokinetics, pharmacodynamics, and clinical efficacy in post-myocardial infarction patients. Circ Cardiovasc Interv 4:422-428. https://doi.org/10.1161/ CIRCINTERVENTIONS.111.963025

37. Mega JL, Close SL, Wiviott SD et al (2009) Cytochrome P-450 polymorphisms and response to Clopidogrel. N Engl J Med 360: 354-362. https://doi.org/10.1056/NEJMoa0809171

38. Kobayashi M, Kajiwara M, Hasegawa S (2015) A randomized study of the safety, tolerability, pharmacodynamics, and pharmacokinetics of clopidogrel in three different CYP2C19 genotype groups of healthy Japanese subjects. J Atheroscler Thromb 22:1186-1196. https://doi.org/10.5551/jat.28639

39. Tiroch KA, Sibbing D, Koch W et al (2010) Protective effect of the CYP2C19 *17 polymorphism with increased activation of clopidogrel on cardiovascular events. Am Heart J 160:506-512

40. Harmsze AM, van Werkum JW, Hackeng CM et al (2012) The influence of CYP $2 \mathrm{C} 19 * 2$ and $* 17$ on on-treatment platelet reactivity and bleeding events in patients undergoing elective coronary stenting. Pharmacogenet Genomics 22:169-175. https://doi.org/ 10.1097/FPC.0b013e32834ff6e3

41. Lewis JP, Stephens SH, Horenstein RB et al (2013) The CYP2C19*17 variant is not independently associated with clopidogrel response. J Thromb Haemost 11:1640-1646. https:// doi.org/10.1111/jth.12342

42. Pedersen RS, Nielsen F, Stage TB et al (2014) CYP2C19*17 increases clopidogrel-mediated platelet inhibition but does not alter the pharmacokinetics of the active metabolite of clopidogrel. Clin Exp Pharmacol Physiol 41:870-878. https://doi.org/10.1111/14401681.12297

43. Su J, Xu J, Li X et al (2012) ABCB1 C3435T polymorphism and response to clopidogrel treatment in coronary artery disease (CAD) patients: a meta-analysis. PLoS One 7:e46366. https://doi.org/10. 1371/journal.pone. 0046366

44. Taubert D, von Beckerath N, Grimberg G et al (2006) Impact of Pglycoprotein on clopidogrel absorption. Clin Pharmacol Ther 80: 486-501. https://doi.org/10.1016/j.clpt.2006.07.007

45. Wang X-Q, Shen C-L, Wang B-N et al (2015) Genetic polymorphisms of CYP2C19 2 and ABCB1 C3435T affect the pharmacokinetic and pharmacodynamic responses to clopidogrel in 401 patients with acute coronary syndrome. Gene 558:200-207. https:// doi.org/10.1016/j.gene.2014.12.051

46. Carlquist JF, Knight S, Horne BD et al (2013) Cardiovascular risk among patients on clopidogrel anti-platelet therapy after placement of drug-eluting stents is modified by genetic variants in both the CYP2C19 and ABCB1 genes. Thromb Haemost 109:744-754. https://doi.org/10.1160/TH12-05-0336

47. Jiang J, Tang Q, Feng J et al (2016) Association between SLCO1B1 $-521 \mathrm{~T}>\mathrm{C}$ and $-388 \mathrm{~A}>\mathrm{G}$ polymorphisms and risk of statin-induced adverse drug reactions: a meta-analysis. SpringerPlus 5:1368. https://doi.org/10.1186/s40064-016-2912-z

48. Samant S, Jiang XL, Peletier LA et al (2017) Identifying clinically relevant sources of variability: the clopidogrel challenge. Clin Pharmacol Ther 101:264-273. https://doi.org/10. 1002/cpt.459 